\title{
Capsaicin-induced CGRP-mediated vasodilatation of the human skin: influence of gender, female hormones and migraine
}

\author{
SGG Vermeersch ${ }^{1 *}$, P Frederiks ${ }^{1}$, A Maassen VandenBrink ${ }^{2}$, J de Hoon ${ }^{1}$ \\ From The European Headache and Migraine Trust International Congress \\ London, UK. 20-23 September 2012
}

Migraine is much more common in women than in men. It is associated with changes in female sex hormone levels with peaks of migraine frequency occurring when estrogen levels drop. Calcitonin gene-related peptide (CGRP) is a potent vasodilating neuropeptide with a pivotal role in migraine headache. Endogenous release of CGRP is induced by capsaicin through activation of the transient receptor potential vanilloid 1 (TRPV1) channel. This study aimed to investigate the influence of gender, hormonal changes and migraine on dermal blood flow (DBF) resulting from capsaicin-induced release of CGRP.

Healthy, non-smoking female volunteers $(n=16)$ not using hormonal contraceptives, were investigated weekly during 2 menstrual cycles. Weekly, two doses of capsaicin (300 and $1000 \mu \mathrm{g}$ ) and vehicle were applied topically on the skin of both forearms. DBF was assessed before and at 10, 20, 30 and 40 minutes after capsaicin/vehicle application using laser Doppler imaging. DBF is expressed as percentage increase versus baseline and presented as areaunder-the-curve from 0 to 40 minutes (AUC, \%.min, mean \pm SEM).

Period differences in capsaicin-induced DBF were observed after both doses of capsaicin $(\mathrm{p}<0.001$, repeatedmeasures ANOVA). During menstruation, capsaicininduced DBF, expressed as AUC, was larger after $300 \mu \mathrm{g}$ ( $1488 \pm 178$ versus $1228 \pm 157 \%$.min, $\mathrm{p}=0.019$; paired T-test) and $1000 \mu \mathrm{g}$ of capsaicin $(1639 \pm 150$ versus 1394 $\pm 163 \%$.min, $\mathrm{p}=0.014$ ) compared to the second week of the secretory phase of the menstrual cycle. Analyses of gender differences and migraine patients versus healthy subjects are ongoing and will be presented at the meeting.

\section{Conclusion}

In healthy women, a hormonal influence on capsaicininduced CGRP-mediated vasodilation of the skin is observed. In particular, an increased dermal blood flow response is documented during the menstruation period. This could be the result of increased neuronal sensitivity to capsaicin, increased release of CGRP or increased sensitivity to CGRP. These results support the hypothesis that female hormones are related to the susceptibility to migraine.

\section{Author details}

${ }^{1}$ Center for Clinical Pharmacology, University Hospitals Leuven, Campus Gasthuisberg, (KU Leuven), Belgium. ²Division of Vascular Medicine and Pharmacology, Department of Internal Medicine, Erasmus MC, Netherlands.

Published: 21 February 2013

\section{References}

1. Van der Schueren B, et al: . Br J Clin Pharmacol 2007, 64:580-590. 2. Van der Schueren B, et al: . J Pharmacol Exp Ther 2008, 325:248-255.

\section{doi:10.1186/1129-2377-14-S1-P124}

Cite this article as: Vermeersch et al:: Capsaicin-induced CGRP-mediated vasodilatation of the human skin: influence of gender, female hormones and migraine. The Journal of Headache and Pain 2013 14(Suppl 1):P124. 